\section{Cureus}

Received 03/08/2019

Review began 03/11/2019

Review ended 03/11/2019

Published 03/13/2019

\section{(c) Copyright 2019}

Ravindranath Waikar et al. This is an open access article distributed under the terms of the Creative Commons Attribution License CC-BY 3.0., which permits unrestricted use, distribution, and reproduction in any medium, provided the original author and source are credited.

\title{
A Unique Pathogen Causing Infective Endocarditis in a Three-year-old Girl
}

\author{
Apoorva Ravindranath Waikar ${ }^{1}$, Omosede Uzamere $^{2}$, Kaneisha Bailey ${ }^{1}$, Louisdon Pierre ${ }^{1}$, \\ Adebayo Adeyinka ${ }^{1}$
}

1. Pediatrics, The Brooklyn Hospital Center, Brooklyn, USA 2. Pediatrics, The Brookyln Hospital Center, Brooklyn, USA

$\square$ Corresponding author: Apoorva Ravindranath Waikar, waikar.apoorva@gmail.com Disclosures can be found in Additional Information at the end of the article

\section{Abstract}

The overall incidence of infective endocarditis (IE) in adults has been reported to be 1.5 to 6.0 per 100,000 patient-years. In children, the incidence of IE in the general population is approximately three times lower. The presence of cyanotic congenital heart disease is considered to be the most strongly associated risk factor to develop IE. In approximately $8 \%$ to $10 \%$ of pediatric cases, IE develops without structural heart disease or any other readily identifiable risk factors. In these situations, the infection usually involves the aortic or mitral valve secondary to Staphylococcus aureus bacteremia. Streptococcus pneumoniae endocarditis in a female with no known risk factors is extremely rare and has no established optimal therapy. We hereby present a case of a three-year-old girl, with no identifiable risk factors diagnosed with IE caused by $S$. pneumoniae.

Categories: Cardiology, Pediatrics, Infectious Disease

Keywords: infective endocarditis, invasive pneumococcal disease, pediatric infections, pneumococcus, pneumococcal endocarditis, pediatric infective endocarditis, pediatric cardiology

\section{Introduction}

Infective endocarditis (IE) occurs less commonly in children than in adults. A study by Pasquali et al. noted the annual incidence rate for IE in children in the United States to be between 0.05 and 0.12 cases per 1000 pediatric admissions from 2003 to 2010 [1]. The epidemiology of heart disease in children has changed during the past three to four decades. Rosenthal et al. in a retrospective study over a 12-year period noted that the proportion of subjects infected with Streptococcal species has declined, whereas the proportion of those infected with Staphylococcal species increased in the post-antibiotic era [2]. Because of the increased survival rate of children with congenital heart disease and the overall decrease in rheumatic valvular heart disease in developed countries, congenital heart disease now constitutes the predominant underlying condition for IE in children over the age of two years in developed countries [3].

\section{Case Presentation}

A three-year-old female presented to our emergency department with a three-week history of productive cough, rhinorrhea, non-bloody non-bilious emesis, and intermittent fevers with a maximum temperature of $102{ }^{\circ} \mathrm{F}$. The child was treated for pneumonia on two occasions in the past six months. There was also a history of recurrent ear infections and she was diagnosed to have moderate persistent asthma a year ago. Her birth history was uncomplicated and there was no history of any structural heart disease or any other congenital defects. The child was up 
to date with vaccines including four doses of pneumococcal conjugate vaccine (PCV)13. There was no family history of recurrent infections, immunodeficiency, consanguinity, or cardiac problems.

On detailed physical exam, subcostal retractions were noted with crackles and decreased air entry on the right side. In light of the respiratory distress, a chest radiograph was obtained and demonstrated an opacification in the right lower lobe, and hence she was admitted with a diagnosis of pneumonia. The following morning, a new soft 2/6 systolic murmur was auscultated over the cardiac apex. Cardiac echocardiography was performed, which revealed 3$\mathrm{mm}$ vegetation on the anterior mitral valve leaflet. Initial laboratory evaluation showed a white count of $23 \times 10^{3} / \mathrm{cu}^{\mathrm{mm}}{ }^{3}$, with $83.4 \%$ neutrophils. Her C-reactive protein (CRP) and erythrocyte sedimentation rate (ESR) were $131.17 \mathrm{mg} / \mathrm{dL}$ and $35 \mathrm{~mm} / \mathrm{hr}$, respectively. Human immunodeficiency virus (HIV) test was resulted to be negative. The primary blood culture grew Streptococcus pneumoniae, serotype 3N sensitive to penicillin G and ceftriaxone. Based on the clinical finding of a new murmur with cardiac vegetations on the echocardiogram and the blood culture report, the patient was diagnosed to have IE and was treated with IV ceftriaxone for four weeks. CBC and CRP were trended throughout her hospital stay until her leukocytosis resolved and CRP normalized. Follow-up echocardiogram one month later showed resolution of vegetation and the murmur.

\section{Final diagnosis}

The final diagnosis was IE due to $S$. pneumoniae, serotype $3 \mathrm{~N}$.

\section{Discussion}

IE in the absence of coronary heart disease (CHD) is often associated with central indwelling venous catheters. In addition to CHD, the high-risk groups for IE in pediatric population include children with noncardiac congenital malformations, malignancies, genetic syndromes, and prematurity and those who have been treated by either invasive procedures including intravenous medications [3-5]. In approximately $8 \%$ to $10 \%$ of pediatric cases, IE develops without structural heart disease or any other risk factors and usually involves the aortic or mitral valve secondary to Staphylococcus aureus bacteremia [6]. The incidence of IE in children with no risk factors is showing an upward trend although the exact numbers are unclear [5]. A Canadian study by Marrie et al. on 3,251 adult patients with invasive pneumococcal disease (IPD) showed the rate of pneumococcal endocarditis complicating IPD to be $0.86 \%$ [7]. Endocarditis due to $S$. pneumoniae accounts for $3 \%$ to $7 \%$ of all cases of childhood endocarditis $[2]$.

Researchers from the Mayo Clinic studied the characteristics of IE in 97 children from 19502011. Staph. aureus and Viridans streptococci were the most common pathogens isolated [8]. Only one out of these 97 had pneumococcal endocarditis; however, the presence or absence of risk factors in this subject is unknown. This finding is backed by researchers, Lin et al., and a systematic review by Vogku et al., who note that apart from Viridans Group Streptococci and Staph. aureus, coagulase-negative Staphylococci (CoNS) is the third most common pathogen of IE [9-10]. A five-year study in Japan by Ishiwada et al. comprising of 170 children with endocarditis had two boys with no risk factors with a pneumococcal etiology [11]. Givner et al. published the findings of US Pediatric Multicenter Pneumococcal Surveillance Group who prospectively identified children seen at eight major centers with invasive disease due to $S$. pneumoniae during the period of 1st September 1993 through 28th February 2003 [12]. During the 10 -year period, the study group identified a total of 3,065 children with pneumococcal bacteremia of which only 11 cases of pneumococcal endocarditis $(0.4 \%)$ were identified. Of these 11 cases, only one child had no history of structural heart disease [12]. In concordance with other studies and adult data, a male preponderance was noted with $73 \%$ of the subjects 
being males [12-13]. Our patient, being a female with no history of any structural heart defect or other risk factors, makes this an unusual presentation of pneumococcal endocarditis.

Community pathogens, such as $S$. aureus, $S$. pneumoniae, Kingella kingae, and Hemophilus species have been found to affect children with no predisposing risk factors [5]. Three studies review IE in children with no structural heart disease and predisposing factors $[5,9,14]$. The characteristics of endocarditis vary in children with and without risk factors. The most striking finding is the acute fulminant course and a high complication rate in children with no predisposing factors [15]. Although considered an uncommon infection, pneumococcal endocarditis has been associated with high mortality rates [16-17]. High mortality rate might be present despite rapid eradication of the pathogen from the blood with complications manifested by severe CHF and embolic phenomena, mainly to the central nervous system (CNS) secondary to large left-sided vegetations $[5,18]$.

The management of IE in children comprises both medical as well as surgical interventions. While parenteral antibiotic therapy is still the first-line treatment, due to the rapid progression of pneumococcal IE, early and timed surgical intervention may be essential to improve survival [19-20]. The use of surgery is necessary in case of cardiac complications such as heart failure, perforation, rupture or abscess of the valve, endocarditis on prosthetic valve, or embolic complications. Other indications for surgical interventions include fungal endocarditis, certain gram-negative bacilli (Serratia marcescens, Pseudomonas spp.), or in cases of persistent bacteremia despite good antibiotic therapy [20].

\section{Conclusions}

Pneumococcal endocarditis should be considered among children with no known risk factors for IE. Because of the potential for multidrug resistance and the infrequency of pneumococcal IE, no optimal therapy has been established for this illness. Treatment is usually cephalosporin alone or a combination of third- or fourth-generation cephalosporin with vancomycin. Early isolation of the pathogen with antibiotic sensitivity and IV antibiotics provides a greater chance of resolution of the disease process. This appears consistent with the findings in the scientific statement from the American Heart Association.

\section{Additional Information \\ Disclosures}

Human subjects: Consent was obtained by all participants in this study. The Brooklyn Hospital Center IRB, Brooklyn, NY issued approval 1245414-1. Thank you for submitting the Publication materials for this case report submission. The Brooklyn Hospital Center IRB has ACKNOWLEDGED your submission and deemed it NOT RESEARCH. No further action on submission 1245414-1 is required at this time. The following items are acknowledged in this submission: • Abstract/Summary - Case report • Application Form - Case report application • Consent Form for Case Reports If you have any questions, please contact Twyla Tate at 718250-6947 or ttate@tbh.org. Please include your project title and reference number in all correspondence with this committee. Conflicts of interest: In compliance with the ICMJE uniform disclosure form, all authors declare the following: Payment/services info: All authors have declared that no financial support was received from any organization for the submitted work. Financial relationships: All authors have declared that they have no financial relationships at present or within the previous three years with any organizations that might have an interest in the submitted work. Other relationships: All authors have declared that there are no other relationships or activities that could appear to have influenced the submitted work. 


\section{References}

1. Pasquali SK, He X, Mohamad Z, McCrindle BW, Newburger JW, Li JS, Shah SS: Trends in endocarditis hospitalizations at US children's hospitals: impact of the 2007 American Heart Association Antibiotic Prophylaxis Guidelines. Am Heart J. 2012, 163:894-899. 10.1016/j.ahj.2012.03.002

2. Rosenthal LB, Feja KN, Levasseur SM, Alba LR, Gersony W, Saiman L: The changing epidemiology of pediatric endocarditis at a Children's Hospital over seven decades. Pediatr Cardiol. 2010, 31:813-820. 10.1007/s00246-010-9709-6

3. Ferrieri P, Gewitz MH, Gerber MA, et al.: Unique features of infective endocarditis in childhood. Pediatrics. 2002, 109:931-943.

4. Day MD, Gauvreau K, Shulman S, Newburger JW: Characteristics of children hospitalized with infective endocarditis. Circulation. 2009, 119:865-870. 10.1161/CIRCULATIONAHA.108.798751

5. Marom D, Levy I, Gutwein O, Birk E, Ashkenazi S: Healthcare-associated versus communityassociated infective endocarditis in children. Pediatr Infect Dis J. 2011, 30:585-588. 10.1097/INF.0b013e31820f66c7

6. Baltimore RS, Gewitz M, Baddour LM, et al.: Infective endocarditis in childhood: 2015 Update: a scientific statement from the American Heart Association. Circulation. 2015, 132:14871515. 10.1161/CIR.0000000000000298

7. Marrie TJ, Tyrrell GJ, Majumdar SR, Eurich DT: Risk factors for pneumococcal endocarditis . Eur J Clin Microbiol Infect Dis. 2018, 37:277-280. 10.1007/s10096-017-3128-z

8. Johnson JA, Boyce TG, Cetta F, Steckelberg JM, Johnson JN: Infective endocarditis in the pediatric patient: a 60-year single-institution review. Mayo Clin Proc. 2012, 87:629-635. 10.1016/j.mayocp.2012.02.023

9. Lin YT, Hsieh KS, Chen YS, Huang IF, Cheng MF: Infective endocarditis in children without underlying heart disease. J Microbiol Immunol Infect. 2013, 46:121-128.

10.1016/j.jmii.2012.05.001

10. Vogkou CT, Vlachogiannis NI, Palaiodimos L, Kousoulis AA: The causative agents in infective endocarditis: a systematic review comprising 33,214 cases. Eur J Clin Microbiol Infect Dis. 2016, 35:1227-1245. 10.1007/s10096-016-2660-6

11. Ishiwada N, Niwa K, Tateno S, Yoshinaga M, Terai M, Nakazawa M: Pneumococcal endocarditis in children: a nationwide survey in Japan. Int J Cardiol. 2008, 123:298-301. 10.1016/j.ijcard.2006.12.016

12. Givner LB, Mason EO Jr, Tan TQ, et al.: Pneumococcal endocarditis in children . Clin Infect Dis. 2004, 38:1273-1278. 10.1086/383323

13. Cahill TJ, Prendergast BD: Infective endocarditis. Lancet. 2016, 387:882-893. 10.1016/S01406736(15)00067-7

14. Le Guillou S, Casalta JP, Fraisse A, Kreitmann B, Chabrol B, Dubus JC, Bosdure E: Infective endocarditis in children without underlying heart disease: a retrospective study analyzing 11 cases. Arch Pediatr. 2010, 17:1047-1055. 10.1016/j.arcped.2010.03.019

15. Martin JM, Neches WH, Wald ER: Infective endocarditis: 35 years of experience at a children's hospital. Clin Infect Dis. 1997, 24:669-675.

16. Powderly WG, Stanley SL, Medoff G: Pneumococcal endocarditis: report of a series and review of the literature. Rev Infect Dis. 1986, 8:786-791. 10.1093/clinids/8.5.786

17. Siegel M, Timpone J: Penicillin-resistant Streptococcus pneumoniae endocarditis: a case report and review. Clin Infect Dis. 2001, 32:972-974. 10.1086/319341

18. Elward K, Hruby N, Christy C: Pneumococcal endocarditis in infants and children: report of a case and review of the literature. Pediatr Infect Dis J. 1990, 9:652-657.

19. Aronin SI, Mukherjee SK, West JC, Cooney EL: Review of Pneumococcal endocarditis in adults in the penicillin era. Clin Infect Dis. 1998, 26:165-171. 10.1086/516279

20. Baddour LM, Wilson WR, Bayer AS, et al.: Infective endocarditis: diagnosis, antimicrobial therapy, and management of complications: a statement for healthcare professionals from the Committee on Rheumatic Fever, Endocarditis, and Kawasaki Disease, Council on Cardiovascular Disease in the Young, and the Councils on Clinical Cardiology, Stroke, and Cardiovascular Surgery and Anesthesia, American Heart Association: endorsed by the Infectious Diseases Society of America. Circulation. 2005, 111:394-434.

10.1161/CIRCULATIONAHA.105.165564 